\title{
HYPOTHESIS
}

\section{Speculations on Disease States Induced by Excitatory Amino Acids}

\author{
John Turnbull
}

\begin{abstract}
There is much current interest in excitatory amino acids and their receptors because of their postulated involvement in several disorders of the nervous system. They function as neurotransmitters, but can act as neurotoxins in some situations. They have been implicated in the pathogenesis of cerebral hypoxic/ischemic and hypoglycemic damage, in epilepsy, in some degenerative diseases, and in some forms of neurotoxin-induced cerebral dysfunction. These diseases may reflect abnormality in a system which has evolved to provide synaptic plasticity essential for learning and memory. The purpose of this paper is to explore the ramifications of such a hypothesis.
\end{abstract} RÉSUMÉ: Spéculations sur la nature des maladies causées par les acides aminés excitateurs Des recherches récentes
ont impliqué les acides aminés excitateurs et leurs récepteurs dans plusieurs désordres du système nerveux central.
Ce sont des neurotransmetteurs qui peuvent parfois agir comme des neurotoxines. On les a impliqués dans la
pathogenèse de l'atteinte cérébrale d'origine hypoxique/ischémique et hypoglycémique, dans l'épilepsie, dans
certaines maladies dégénératives et dans d'autres formes de dommage neurotoxicologique. On les a également
impliqués dans la genèse de la plasticité synaptique si fondamentale pour l'apprentissage et la mémoire. Il se peut que
les atteintes pathologiques soient une maladaption de ce système dont l'évolution en premier lieu visait à fournir une
plasticité synaptique dans des conditions physiologiques. Cet article a pour but d'explorer les différentes facettes de
cette hypothèse.
Can.J. Neurol. Sci. 1987; 14:122-126

There is much current interest in excitatory amino acids and their receptors because of their postulated involvement in several disorders of the nervous sytem. The most common excitatory amino acids are glutamate and aspartate, but others are also of importance. They function as excitatory neurotransmitters, but it has been recognised for some years that they can also act as neurotoxins ('excitotoxins'). 'They have been implicated in the pathogenesis of cerebral ischemic and hypoglycemic damage, in epilepsy, in some degenerative diseases, and in some forms of neurotoxin-induced cerebral dysfunction. As well, they have been postulated to underlie the genesis of learning and memory. If these different lines of investigation are borne out, it would seem unlikely that there would not exist some unifying mechanism to explain the multiple roles of excitatory amino acids. The purpose of this paper is to explore the ramifications of such a hypothesis. Some of the evidence implicating excitatory amino acids in the phenomena listed above will first be reviewed.

\section{Cerebral Hypoxia/Ischemia}

The role of the excitatory amino acids in the pathogenesis of cerebral hypoxic/ischemic damage is the object of intense research efforts, and has recently been reviewed. ${ }^{2}$ There is a growing body of evidence suggesting that the neuronal cell damage which follows cerebral hypoxic/ischemic insult may not be the result of the hypoxia per se. It has been established that neuronal cells in culture are relatively insensitive to hypoxic challenge until they have established dendritic connections. ${ }^{3}$ In these culture systems the hypoxic insult can be greatly attenuated by pretreatment with blockers of excitatory amino acid receptors, ${ }^{4}$ and indeed, cytotoxic changes identical to those following hypoxia can be produced by the transient addition of these transmitters to the culture medium. ${ }^{5}$ This would suggest that hypoxic/ischemic cell death might result from the uncontrolled release of excitatory amino acids. In the rat, ischemic damage to the hippocampus can be greatly reduced if the perforant pathway (carrying the major excitatory amino acid input to the hippocampus) is first cut. $^{6}$ The same protective effect is not seen in animals with lesions to the fimbria/fornix, which carries the main cholinergic and serotinergic inputs to the hippocampus. ${ }^{6}$ Injection of glutamate receptor blockers into the hippocampus provides local protection to subsequent ischemic challenge. ${ }^{7}$ Human trials using specific blockers of the excitatory amino acid receptors in situations where transient ischemia might be expected are proposed. 5

\section{Epilepsy}

Analogues of excitatory amino acids are highly epileptogenic, ${ }^{8}$ while antagonists such as D-2-amino-7-phosphonoheptanoate 
(D-AP7) have potent anti-epileptic activity in rodents and monkeys. ${ }^{9}$ Indeed, when administered intrathecally they are among the most potent anti-epileptic agents thus far discovered. ${ }^{8}$ Moreover, it has recently been shown that kindling of the angular bundle leads to an increase in glutamate binding sites on hippocampal synaptic membranes. ${ }^{10}$ Thus, there is evidence implicating the excitatory amino acids in the pathogenesis of both seizures and kindling. Attempts to introduce glutamate antagonists as anti-epileptic medications have so far been limited by the low permeability of the blood brain barrier to these agents. ${ }^{11}$

\section{Neurotoxicology}

Some neurotoxins such as L-3-oxalylamino-2-amino-propionic acid (ODAP) extracted from the pea Lathyrus sativus act preferentially on excitatory amino acid receptors. ${ }^{12}$ Clinical neurolathyrism is characterised chiefly by spastic paraparesis. The effects of ODAP are mediated by stimulation of a particular type of excitatory amino acid receptor ('kainate' receptor). ${ }^{12}$ Neurotoxins such as trimethyl tin have high specificity for the limbic system, ${ }^{13}$ but questions still remain about the nature of their effects on excitatory amino acid receptors. As discussed below, there has been some speculation about the role of endogenous neurotoxins in the causation of human neurodegenerative disease.

\section{Degenerative Diseases}

The endogenous neurotoxin quinolinic acid acts as an agonist to excitatory amino acid receptors, and its level is increased in senescent rats. It has been speculated that it may play a role in the genesis of the neuronal destruction in degenerative diseases such as Huntington's Disease ${ }^{14}$ and Alzheimer's Disease. ${ }^{15}$ Alternatively, Cotman et al ${ }^{16}$ have postulated that the reduction in the afferent input to the hippocampi from the entorhinal cortex in Alzheimer's Disease leads to collateral sprouting in nearby unaffected excitatory pathways, both extrinsinc (septal) and intrinsic (commisural and associational), with a corresponding increase in the excitatory amino acid receptor density in the dentate and hippocampus which may be detrimental. Some of the inherited ataxias are related to glutamate dehydrogenase deficiency, ${ }^{17}$ perhaps leading to a relative overactivity of excitatory amino acid functions (due to enhanced levels of glutamate) in certain parts of the brain.

\section{Learning and Memory}

In the past few years, animal models for human memory have been developed. In these models, induction of brief but intense activity in cortical and hippocampal pathways produces increases in post-synaptic potentials that can persist for months, ${ }^{18}$ a phenomenon termed long term potentiation (LTP). LTP is induced by brief physiological events, ${ }^{19}$ is strenghtened by repetition ${ }^{20}$ and can persist indefinitely, ${ }^{18}$ and thus exhibits the properties expected in human memory. It has recently been shown that pharmacological manipulations which prevent the induction of LTP result in selective impairment of learning. ${ }^{21}$ Since LTP can be carried out in vitro using brain slices, and is amenable to study at a celiular and sub-cellular level, it has made an interesting experimental model for the study of human memory.

The biochemical basis of LTP has been partially elucidated. Glutamate and aspartate are transmitters in several hippocampal pathways including those that exhibit LTP ${ }^{22}$ Drugs that block certain glutamate and aspartate receptors also inhibit synaptic transmission in these hippocampal pathways, and LTP cannot be induced during the pharmacological block. ${ }^{23}$ Thus, there is good evidence linking the excitatory amino acids with LTP. Since one ion channel under their control permits an important local influx of calcium when activated, subsequent events may be predicated on this rise. However, the nature of these events is still uncertain. There is accumulating evidence that calciumrequiring protein kinases may be implicated. In particular, it has been shown that protein phosphorylation due to the action of protein kinase C occurs with LTP, ${ }^{24}$ and there is speculation that this leads in some way to a modified synapse. ${ }^{25}$ Alternatively, Baudry and Lynch ${ }^{26}$ suggest that modifications to the synapse follow the activation of a calcium-dependent intracellular protease named calpain which leads to an enzymatic modification of a cytoskeletal structural protein involved in receptor expression and synaptic structure. ${ }^{27-31}$ There are several endogenous substrates to calpain including the microtubule associated proteins and a structural protein called fodrin or brain spectrin, ${ }^{26}$ which is similar to the structural protein spectrin known to be involved in receptor expression in blood cells. ${ }^{32}$ Rats receiving an intraventricular infusion of leupeptin, a potent inhibitor of calpain, performed less well than control rats receiving either saline or aprotinin, a non-specific serine proteinase, in both spatial mazes and smell-discriminative learning. ${ }^{26}$ However, there are some significant problems with this hypothesis ${ }^{33}$ and it is possible that the main importance of calpain will prove to be its unwanted activation in certain disease states.

It is important to bear in mind that in other animal models of memory, such as the habitutation and sensitization of reflex activity in Aplysia, the synaptic plasticity appears pre-synaptic and not related to excitatory amino acid activity. ${ }^{34}$ The role of these mechanisms in human memory is still undetermined.

\section{The ExCitatory AMino ACID RECEPTORS}

During the last few years, there have been considerable advances in our knowledge of excitatory amino acid receptors. ${ }^{33}$ It now appears that there are at least three different types of receptors (NMDA, quisqualate, and kainate, sometimes simply referred to as 'Al', 'A2', 'A3' respectively) all stimulated by glutamate and aspartate, but differing in their affinity for various analogues of these amino acids. ${ }^{35}$ Of these receptor types the most interesting and best defined is the NMDA receptor, so named because it interacts preferentially with N-Methyl-DAspartate. Evidence suggests that this receptor is both voltage and transmitter regulated. It may not function in low frequency discharges, but is involved in high frequency transmission, and is implicated in LTP. ${ }^{33}$ The ion channel the receptor controls seems to be blocked under normal circumstances with magnesium, and possibly other divalent cations, in a voltage dependant fashion. ${ }^{33}$ However, when the cell membrane is sufficiently depolarized the channel is no longer blocked and an important influx of calcium occurs. One could postulate that such a system has evolved to transform a graded receptor function into an all or none event, which would be ideally suited to the elimination of random noise, and the encoding of meaningful information only.

\section{HYPCTHESIS}

One feature which emerges from the above is the central role that excitatory amino acids seem to play in diseases of higher 
cortical function of more evolved species. It is possible that all of these diseases adversely affect a single physiological system which has evolved for other reasons. Based on the above evidence, one likely candidate is the system which has evolved to permit permanent synaptic modifications in response to different experiential circumstances and which is represented in greatest degree in learning and memory. This is a system which confers great advantage to the species in which it is well represented. One might speculate that a price higher organisms have paid for the evolutionary advantage conferred by highly advanced mechanisms of synaptic plasticity is an increased susceptibility to global and focal cerebral hypoxic/ischemic damage, epilepsy, and possibly to some neurotoxic and neurodegenerative diseases as well.

If indeed these diseases result from an aberration of the normal physiological mechanisms providing for central synaptic plasticity most evident in learning and memory, then any similarities would then be consequent and not coincident, and advances in one field of research would bear directly on the others. In this way one could make speculations about which future research efforts might be fruitful based on advances in the other domains.

\section{Implications for Epilepsy}

As pointed out some years ago, the phenomenon of kindling shares many features with that of learning. ${ }^{36} \mathrm{It}$ is probable that the nature of this similarity soon will become much clearer. Indeed, if the engram proposed for learning is applicable to epilepsy, then several readily testable predictions could be made which might be of both theoretical and practical interest in epilepsy research. Firstly, one could predict that a seizure should be clearly divorceable from the kindling of a seizure focus. That is, membrane depolarization through the action of excitatory synapses might lead to a seizure, but permanent facilitatory changes to the synapse would not ensue unless the subsequent synaptic kinase or protease systems were activated. Similarly their activation might cause permanent facilitatory synaptic changes without a necessary antecedent seizure, and if the model of Lynch and Baudry is correct leupeptin might prevent kindling but not affect the seizure threshold per se. Another speculation concerns the potential side-effects of proposed anti-epileptic medications such as D-AP7, since there would be a real danger that these drugs might selectively interfere with memory. As well, any medication useful in preventing kindling might prove deleterious in learning, possibly without affecting established memory. For a condition which may require life-long treatment, this would have important consequences, perhaps even limiting the clinical utility of these agents. The analogy between kindling and learning might also explain why epileptiform activity tends to become manifest in the temporal lobes as the epileptic ages ${ }^{37}$ since it is the temporal lobes which seem to have the greatest potential for synaptic plasticity in memory. In addition, since excitatory amino acids have definite neurotoxic potential, longterm overactivity in excitatory amino acid circuits, either independently or concomitantly with hypoxic stress, might explain the hippocampal sclerosis seen in epileptics. ${ }^{38}$ One caveat to all this is the observation of Wada ${ }^{39}$ that kindling of a seizure focus is more difficult in higher animals, which would not be predicted by the above logic. The explanation for this may lie in his choice of experimental conditions, but could also imply that our present understanding of the mechanisms of epilepsy is still imperfect. Also unknown is the precise relationship between other coincident excitatory and inhibitory inputs, both neural and hormonal, and their role in the modulation of seizure discharges or kindling. As such, it is a matter of speculation as to whether concomitant pharmacological manipulation of these inputs might be a useful adjunct in either seizure control or in preventing kindling.

\section{Implications for Vascular Disease}

There are many situations wherein a transient hypoxic/ischemic insult could be anticipated and during which time iatrogenic blockade of the excitatory amino acid chain could be undertaken in an attempt to reduce subsequent insult to the brain. There could be reduction in glutamate storage or release, or blockade of excitatory amino acid receptors or their associated channels. As mentioned above, glutamate receptor blockade is being considered as a therapeutic modality in humans, ${ }^{5}$ in situations such as the acute phase of cerebral infarction, cardiac arrest, or bypass surgery. With selective blockers of the glutamate receptor a deficit of learning and memory could be anticipated, but would be of short duration and might even prove beneficial. Parallels from epilepsy research and from models of learning and memory might prove helpful in indicating how other manipulation of the excitatory amino acid chain might be accomplished to further reduce hypoxic/ischemic damage. One could predict that interference with the NMDA channel with high levels of magnesium for example, might have a protective action in ischemia just as it does in seizures. Along these lines, one could also postulate that the dissociative anaesthetics, which also act at least in part at the NMDA receptor ${ }^{40}$ might prove useful in acute cerebral ischemia. If neuronal destruction following ischemia results from the calciuminduced activation of intracellular proteases, blockers of these proteases such as leupeptin, might also prove beneficial. Recently, Rothman ${ }^{41}$ has suggested that the damage results from osmotic rupture of neurons following choride influx under conditions of sustained activation of the glutamate receptor channel, and not from a secondary rise in intra-cellular calcium. Perhaps both mechanisms are operant in certain cases, depending on the length and severity of the insult, and dual blockade (of both receptor and proteases) might be beneficial. Lastly, coactivation of the target cells would hasten membrane depolarization and potentiate NMDA channel opening, and pharmacologically reducing other excitatory inputs or increasing inhibitory ones might be concomitantly beneficial.

\section{Implications for Neurotoxicology and Neurodegenerative Disease}

Neurotoxins acting as agonists on the NMDA receptor would be expected to lower the seizure threshold and to interfere with memory. Although memory deficit following exposure to neurotoxins is undoubtedly heterogenous, several mechanisms of memory loss based on the model of learning and memory could be proposed. As delineated above, there could be blockage of selective excitatory amino acid pathways at any of several sites. Perhaps even more importantly, however, there could also be uncontrolled activation at excitatory synapses leading to non-informative structural changes, and thus dementia. Degenerative changes might also follow the calpain-induced alteration of microtubules or other proteins besides fodrin serving as substrates for calcium-activated enzymes, all of which might occur independently of actual receptor activation. Any of the 
above mechanisms could occur in normal excitatory circuits or, at a lower threshold, in circuits wherein compensatory proliferation of excitatory synapses has occurred secondary to the loss of the primary afferents as suggested by Cotman et al. ${ }^{16}$ It will be a matter of some interest to see the exact effects of known neurotoxins such as trimethyl tin and aluminum on the excitatory amino acid pathway. One important implication for neurotoxicology is the potential of cellular and subcellular techniques used in the field of learning and memory to provide useful in vitro tests of memory impairment caused by neurotoxins.

The search for endogenous or exogenous excitatory neurotoxins producing neurodegenerative diseases will undoubtedly continue, and should probably be widened to include the investigation of neurotoxic effects downstream from the receptor itself. It is possible that activity at different excitatory receptor sub-types will lead to quite different diseases, either because the pathological effects are different, or because the receptor sub-types have different localisations. Thus dementia might follow untowards activity in hippocampal NMDA receptors, while forms of olivopontocerebellar degeneration might occur in genetically susceptible subjects following exposure to ODAP, or similar endogenous or exogenous compounds acting on phylogenetically older kainate receptors in the brainstem, cerebellum, and spinal cord.

\section{Others}

There is some similarity in the neuropathological changes seen in cerebral hypoglycemic change to that caused by presumed involvement of excitatory circuits mentioned above, and there is evidence that hypoglycemic damage can be prevented by NMDA receptor antagonists. ${ }^{42}$ It is possible that other diseases will ultimately be associated with pathology in this system. (For example, could the NMDA receptor be the site of antibody attack or serve as a viral receptor?) Several of these issues will undoubtedly become much clearer with the passage of time.

\section{Conclusion}

Much of the above is speculative, and some may be proven incorrect as the mechanisms of excitotoxic damage become better understood. Eventually, the true importance of excitotoxic damage will become clearer. Nonetheless, the confluence of several lines of research does suggest that at least some disorders of higher neurological function may be due to abnormal activity at synapses initially evolved to provide permanent synaptic plasticity, which in their best-studied form provide the basis of learning and memory. The ramifications of such a hypothesis have been explored. There is legitimate concern that newer therapies in the fields of epilepsy and cerebral ischemic disease will prove to have serious neurotoxic potential, but equally, it is possible that selective differences in neurotoxins might be exploited to develop useful therapies in these fields. As well, it is hoped that the research will lead to rapid, reliable in vitro tests of neurotoxic potential which are not available at present.

\section{REFERENCES}

1. Oleny JW. Excitotoxins: an overview. In: Excitotoxins. Fuxe K, Roberts P, Schwarcz R, eds. Plenum Press, New York 1983; $82-96$.
2. Rothman SM, Olney JW. Glutamate and the pathophysiology of hypoxic ischemic brain damage. Ann Neurol 1986; 19: 105-111.

3. Rothman SM. Synaptic activity mediates death of hypoxic neurons. Science 1983; 220: 536-537.

4. Rothman SM. Synaptic release of excitatory amino acid neurotransmitter mediates anoxic neuronal death. J Neurosci 1984; 4: 1884-1891

5. Meldrum B. Excitatory amino acids and anoxic/ischaemic brain damage. TINS 1985, Feb, 47-48.

6. Wieloch T, Lindvall O, Blomqvist $P$, Gage FH. Evidence for amelioration of ischaemic neuronal damage in the hippocampal formation by lesions of the perforant path. Neurol Res 1985; 7 : 24-26.

7. Simon RP, Swan JH, Griffiths T, Meldrum BS. Blockade of N-methyl$D$-aspartate receptors may protect against ischemic damage in the brain. Science 1984; 266: 850-852.

8. Schwarcz R, Meldrum B. Excitatory amino acid antagonists provide a therapeutic approach to neurological disorders. Lancet 1985; 8447: 140-143.

9. Croucher MJ, Collins JF, Meldrum BS. Anticonvulsant action of excitatory amino acid antagonists. Science 1982; $216: 899-901$.

10. Savage DD, Werling LL, Nadler JV, McNamara JO. Selective and reversible increase in the number of Quisqualate sensitive glutamate binding sites on hippocampal synaptic membranes after angular bundle kindling. Brain Res 1984; 307: 332-335.

11. Fagg GE. L glutamate, excitatory amino acid receptors and brain function. TINS 1985, May, 207-210.

12. MacDonald JF, Morris ME. Lathyrus excitotoxin: mechanism of neuronal excitation by L-2-oxalylamino-3-amino- and L-3-oxalylamino-2-amino-propionic acid. Exp Brain Res 1984; 57: 158-166.

13. Brown AW, Aldridge WN, Street BW, Verschoyle RD. The behavioral and neuropathologic sequelae of intoxication by trimethyltin compounds in the rat. Am J Pathol 1979; 97: 59.

14. Shoulson I. Huntington's disease: anti-neurotoxic therapeutic strategies. In: Excitotoxins. Fuxe K, Roberts P, Schwarcz R, eds. Plenum Press, New York 1983; 343-353.

15. Schwarcz R, Foster A, French AC, Whetsell WO, Kohler C. Excitotoxic models for neurodegenerative disorders. Life Sci 1984; 35: $19-32$.

16. Geddes JW, Monaghan DT, Cotman CW, Lott IT, Kim RC, Chui HC. Plasticity of hippocampal circuitry in Alzheimer's Disease. Science 1985; 230: 1179-1181

17. Plaitakis A, Nicklas WJ, Desnick RJ. Glutamate dehydrogenase deficiency in three patients with spinocerebellar syndrome. Ann Neurol 1980; 7: 297-303.

18. Bliss TVP, Gardner-Medwin AT. Long-lasting potentiation of synaptic transmission in the dentate area of the unanaestetized rabbit following stimulation of the perforant path. J Physiol (Lond) 1973; 232: 357-74.

19. Douglas RM, Goddard GV. Long-term potentiation of the perforant cellpath-granule cell synapse in the rat hippocampus. Brain Res 1975; 86: 205-15.

20. Barnes CA. Memory deficits associated with senescence: a neurophysiological and behavioural study in the rat. J Comp Physiol Psychol 1979; 93: 74-103.

21. Morris RGM, Anderson E, Lynch G, Beaudry M. Selective impairment of learning and blockade of long-term potentiation by an $\mathrm{N}$-methyl-D-aspartate receptor antagonist, AP-5. Nature 1986; 319: 774-776.

22. Storm-Mathiesen J. Localisation of neurotransmitter candidates in the brain: the hippocampal formation as a model. Prog Neurobiol 1977; 8: 119.

23. Dunwiddie TV, Madison D, Lynch GS. Synaptic transmission is required for initiation of long-term potentiation. Brain Res 1978 ; 150: 413-417.

24. Lovinger DM, Colley PA, Akers RF, Nelson RB, Routtenberg A. Direct relation of long-term potentiation to phosphorylation of protein $\mathrm{FI}$, a substrate for membrane protein kinase C. Brain Res 1986; 399: 205-211.

25. Kaczmarek LE. The role of protein kinase $C$ in the regulation of ion channels and neurotransmitter release. TINS 1987 Jan. 30-34.

26. Lynch G, Baudry $M$. The biochemistry of memory: a new and specific hypothesis. Science 1984; 224: 1057-1063.

27. Lynch G, Larson J, Kelso S, Barrionuevo G, Brown T. Intracellular injections of EGTA block induction of hippocampal long- 
term potentiation. Nature [London] 1983; 305: 719-721.

28. Baudry M, Lynch $G$. Regulation of hippocampal glutamate receptors: evidence for the involvement of a calcium activated protease. Proc Natl Acad Sci USA 1980; 77: 2298-2302.

29. Baudry M, Kramer K, Lynch G. Irreversibility and time course of calcium stimulated [3H] glutamate binding to rat hippocampal membranes. Brain Res 1983; 270: 142-145.

30. Baudry M, Smith E, Lynch G. Influence of temperature, detergents, and enzymes on glutamate receptor binding and its regulation by calcium in rat hippocampal membranes. Mol Pharmacol 1981; 20: $280-286$.

31. Siman R, Baudry M, Lynch G. Purification from synaptosomal plasma membranes of Calpain 1, a thiol protease activated by micromolar calcium concentrations. J Neurochem 1983; 41: 950-956.

32. Baldassare JJ, Bakshian S, Knipp MA, Fisher GJ. Inhibition of fibrinogen receptor expression and serotonin release by leupeptin and antipain. J Biol Chem 1985; 260: 10531-10535.

33. Foster AC, Fagg GE. Acidic amino acid binding sites in mammalian neuronal membranes: their characteristics and relationship to synaptic receptors. Brain Res Rev 1984; 7: 103-164.

34. Byrne JH. Neural and molecular mechanisms underlying information storage in Aplysia: implications for learning and memory. TINS 1985; Nov. 478-482.
35. Crunelli V, Forda S, Kelly JS. Excitatory amino acids in the hippocampus: synaptic physiology and pharmacology. TINS 1985; Jan. 26-30.

36. Goddard GV, Douglas RM. Does the engram of kindling model the engram of normal long-term memory? Can J Neurol Sci 1975; 2 : 385-394.

37. Hughes JR. Long-term clinical and EEG changes in patients with epilepsy. Arch Neurol 1985; 42: 213-223.

38. Griffiths T, Evans MC, Meldrum BS. Temporal lobe epilepsy, excitotoxins, and the mechanism of selective neuronal loss. In: Excitotoxins. Fuxe K, Roberts P, Schwarcz R, eds. Plenum Press, New York 1983; 331-342.

39. Wada JA. The clinical relevance of kindling: species, brain sites and seizure susceptibility. In: Limbic mechanisms. Livingston KE, Hornykiewicz O, eds. Plenum Press 1978; 369-388.

40. Honey CR, MacDonald JF. Phencyclidine and Ketamine block aspartic acid responses. Neurosci L 1985; 61: 135-139.

41. Rothman $S$. The neurotoxicity of excitatory amino acids is produced by passive chloride influx. J Neurosci 1985; 5: 1483-1489.

42. Wieloch $\mathrm{T}$. Hypoglycemia-induced neuronal damage prevented by an $\mathrm{N}$-methyl-D-aspartate antagonist. Science 1985;230:681-683. 